\title{
Breast cancer susceptibility: current knowledge and implications for genetic counselling
}

\author{
Tim Ripperger $^{1}$, Dorothea Gadzicki ${ }^{1}$, Alfons Meindl ${ }^{2}$ and Brigitte Schlegelberger*,1 \\ ${ }^{1}$ Institute of Cell and Molecular Pathology, Hannover Medical School, Hannover, Germany; ${ }^{2}$ Department of Obstetrics \\ and Gynaecology, Technical University, Munich, Germany
}

Breast cancer is the most common malignancy in women in the Western world. Except for the high breast cancer risk in $B R C A 1$ and $B R C A 2$ mutation carriers as well as the risk for breast cancer in certain rare syndromes caused by mutations in TP53, STK11, PTEN, CDH1, NF1 or NBN, familial clustering of breast cancer remains largely unexplained. Despite significant efforts, $B R C A 3$ could not be identified, but several reports have recently been published on genes involved in DNA repair and single nucleotide polymorphisms (SNPs) associated with an increased breast cancer risk. Although candidate gene approaches demonstrated moderately increased breast cancer risks for rare mutations in genes involved in DNA repair (ATM, CHEK2, BRIP1, PALB2 and RAD50), genome-wide association studies identified several SNPs as low-penetrance breast cancer susceptibility polymorphisms within genes as well as in chromosomal loci with no known genes (FGFR2, TOX3, LSP1, MAP3K1, TGFB1, 2q35 and 8q). Some of these low-penetrance breast cancer susceptibility polymorphisms also act as modifier genes in $B R C A 1 / B R C A 2$ mutation carriers. This review not only outlines the recent key developments and potential clinical benefit for preventive management and therapy but also discusses the current limitations of genetic testing of variants associated with intermediate and low breast cancer risk.

European Journal of Human Genetics (2009) 17, 722-731; doi:10.1038/ejhg.2008.212; published online 17 December 2008

Keywords: hereditary breast and ovarian cancer; breast cancer susceptibility; low penetrance genes; modifier genes; genetic counselling; single nucleotide polymorphisms (SNPs)

\section{Introduction}

With an average lifetime risk of $8-10 \%$, breast cancer is the most common malignancy in women in the Western world. Up to $15 \%$ of healthy women have at least one firstdegree relative with breast cancer ${ }^{1}$ and empirical data show that breast cancer risk doubles in these women. It is assumed that monogenic traits account for $5 \%$ of breast cancer overall. ${ }^{2}$ Germline BRCA1 or BRCA2 mutations, which account for $20-40 \%$ of breast cancer that clusters in

*Correspondence: Professor Dr B Schlegelberger, Institute of Cell and Molecular Pathology, Hannover Medical School, Carl-Neuberg-Strasse1, 30625 Hannover, Germany.

Tel: + 49511532 4523; Fax: + 49511532 4521;

E-mail: schlegelberger.brigitte@mh-hannover.de

Received 9 January 2008; revised 22 September 2008; accepted 1 October 2008; published online 17 December 2008 families and less than $5 \%$ of breast cancer overall, ${ }^{3}$ are associated with a high lifetime risk of up to $60-85 \%$ for breast cancer as well as an increased risk for ovarian cancer. In addition to this high risk in hereditary breast and ovarian cancer, there are certain heritable syndromes associated with an increased breast cancer risk. However, more than $50 \%$ of the genetic predisposition to familial breast cancer remains unexplained. ${ }^{4-6}$

In this review, an overview of the most recently published breast cancer susceptibility genes and single nucleotide polymorphisms (SNPs) is given. Besides these current findings, many other SNPs linked to breast cancer susceptibility were found in the past, but the objective of this paper is to review the recent findings in breast cancer genetic susceptibility identified in candidate gene approaches of genes involved in DNA repair and huge 
genome-wide association studies. One has to distinguish strictly between rare mutations in genes involved in DNA repair that are associated with a moderate breast cancer risk on the one side and common low penetrance polymorphisms causing a slightly increased breast cancer risk on the other. ${ }^{7}$ These common variants consist of SNPs in known genes such as fibroblast growth factor receptor 2 (FGFR2) and in loci in which the gene or genes responsible have not yet been identified. As for most complex diseases, it is expected that the individual risk for breast cancer is determined by the interaction of several or even many genetic variants, that is, a certain pattern of polymorphisms, and environmental factors, for example, hormones or physical exercise, and not by a single genetic variant. So far, neither the cumulative risk associated with patterns of known low-risk variants has been determined nor have risk prediction models integrating the different genetic variants been developed and validated. This clearly limits the clinical use of these susceptibility mutations and polymorphisms in $B R C A 1 / B R C A 2$ mutation-negative individuals with an increased risk for familial breast cancer as well as in the general population to estimate the individual breast cancer risk for those women who want to learn more about it. ${ }^{8}$ The situation may change in the near future with the identification of further genetic risk factors, the establishment of valid risk prediction models and the use of new generation high-throughput sequencing technologies. Analogous to the guidelines that have been established to support decision-making on whether or not a family should be offered mutation screening in BRCA1 and $B R C A 2,{ }^{1,2,9-14}$ criteria have to be defined for requirements to be fulfilled before genetic testing of intermediate penetrance genes for rare mutations associated with moderate breast cancer risk, and of low penetrance SNPs for common alleles associated with slightly increased breast cancer risks should be implemented in routine diagnostics.

\section{Breast cancer-associated cancer predisposition syndromes}

Hereditary breast and ovarian cancer caused by mutations in BRCA1 or BRCA2 is the most frequent autosomal dominant disorder associated with a high breast cancer risk. ${ }^{6}$ In addition, there are several other rare cancer predisposing syndromes associated with an increased breast cancer risk (Table 1). In Li-Fraumeni syndrome (LFS1, MIM no. 151623), ${ }^{2,20}$ caused by germline mutations in TP53, breast cancer is one of the multiple neoplasias such as soft tissue sarcomas, leukaemia and brain tumours that recurrently occur at a young age. For organizing the clinical management, please refer, for example, to the National Comprehensive Cancer Network (NCCN) guidelines. ${ }^{21}$

In addition, an increased breast cancer risk is present in individuals with Peutz-Jeghers syndrome (MIM no. 175200) carrying heterozygous germline mutations in STK11, formerly known as $L K B 1$, causing a polyposis syndrome characterized by melanocytic macules of the lips, buccal mucosa and digits as well as multiple gastrointestinal hamartomatous polyps and an increased risk of various neoplasms, including breast cancer. ${ }^{19}$ For age-dependent screening procedures, please see the recent review by Lynch et al. ${ }^{22}$

Cowden syndrome (MIM no. 158350), characterized by multiple hamartomas occurring in skin, breast, thyroid, gastrointestinal tract, endometrium and brain as well as an increased risk of malignant tumours, is associated with an increased breast cancer risk of up to $30-50 \%$ by the age of 70 years. In view of the increased cancer risk, intensified screening procedures are indicated. ${ }^{21,22}$ Disease-causing

Table 1 Breast cancer-associated cancer predisposition syndromes

\begin{tabular}{|c|c|c|c|c|c|}
\hline Syndrome $e^{\mathrm{a}}$ & Gene & Name & Location & $\begin{array}{l}\text { Syndrome } \\
\text { prevalence }^{\mathrm{b}}\end{array}$ & Estimated breast cancer risk \\
\hline Cowden syndrome & PTEN & $\begin{array}{l}\text { Phosphatase and tensin } \\
\text { homologue }\end{array}$ & $10 q 23.3$ & $1-9 / 1000000$ & $\begin{array}{l}30-50 \% \text { risk by the age of } \\
70 \text { years }^{15}\end{array}$ \\
\hline $\begin{array}{l}\text { Hereditary diffuse } \\
\text { gastric cancer/familial } \\
\text { lobular breast cancer }\end{array}$ & $\mathrm{CDH} 1$ & Cadherin 1, E-cadherin & $16 q 22.1$ & - & $\begin{array}{l}52 \% \text { risk by the age of } 75 \\
\text { years for } 2398 \text { delC }^{16}\end{array}$ \\
\hline $\begin{array}{l}\text { Li-Fraumeni } \\
\text { syndrome } 1\end{array}$ & TP53 & $\begin{array}{l}\text { Transformation-related } \\
\text { protein } 53\end{array}$ & $17 p 13.1$ & $1-9 / 100000$ & $\begin{array}{l}50-60 \% \text { risk by the age of } \\
45 \text { years }^{2}\end{array}$ \\
\hline $\begin{array}{l}\text { Neurofibromatosis } \\
\text { type I }\end{array}$ & NF1 & Neurofibromin & $17 q 11.2$ & $1-5 / 10000$ & SIR: $3.5^{17}$ \\
\hline $\begin{array}{l}\text { Nijmegen breakage } \\
\text { syndrome }\end{array}$ & $N B N^{c}$ & Nibrin & $8 q 21-24$ & Exceptional & OR: 2.8 for 657 del $5^{18}$ \\
\hline $\begin{array}{l}\text { Peutz-Jeghers } \\
\text { syndrome }\end{array}$ & STK $11^{\mathrm{d}}$ & $\begin{array}{l}\text { Serine/threonine } \\
\text { protein kinase } 11\end{array}$ & $19 p 13.3$ & $1-9 / 100000$ & $\begin{array}{l}45 \% \text { risk by the age of } 70 \\
\text { years }\end{array}$ \\
\hline
\end{tabular}

OR, odds ratio; SIR, standardized incidence ratio.

${ }^{a}$ Alphabetical order.

${ }^{b}$ According to Orphanet (www.orpha.net, 28 June 2008).

${ }^{\mathrm{c}}$ Formerly known as NBS1.

dFormerly known as $L K B 1$. 
germline mutations were commonly found in PTEN, a crucial tumour suppressor in the phosphatidylinositol 3-kinase pathway. ${ }^{15}$ Interestingly, a recent report on the subsequent sequence analysis of PTEN in BRCA1/BRCA2 mutation-negative individuals in 98 French-Canadian breast cancer cases from high-risk breast/ovarian cancer families failed to identify mutations in the coding region of PTEN, whereas four variants in intronic sequences were found that do not seem to alter RNA splicing or PTEN protein levels. ${ }^{15}$ In contrast, Saal et $a l^{23}$ recently reported on PTEN expression loss in basal-like breast cancer associated with somatic PTEN-coding mutations in BRCA1 wild-type carriers and 'gross' PTEN mutations, that is, intragenic chromosome breaks, inversions, deletions and microcopy number aberrations in heterozygous BRCA1 mutation carriers.

CDH1 mutations are known to cause hereditary diffuse gastric cancer and/or lobular breast cancer. ${ }^{16}$ Even in families without diffuse gastric cancer in their medical history, CDH1 mutations could be found in women with lobular breast cancer. ${ }^{24}$ In view of the increased cancer risk, intensified surveillance programmes are indicated. ${ }^{22,25}$

For women with neurofibromatosis type I (NF1) (MIM no. 162200), an autosomal dominant disorder caused by NF1 mutations, a moderately increased breast cancer risk was reported. Therefore, early screening has to be considered in these women by an interdisciplinary team of experts. $^{17}$

Nijmegen breakage syndrome (MIM no. 251260), an autosomal recessive chromosomal instability syndrome characterized by microcephaly, growth retardation, immunodeficiency and predisposition to different malignancies, is caused by mutations in NBN, known to be involved in DNA repair. ${ }^{26}$ Recently, a 5 bp deletion in NBN (657del5) was shown to be associated with an almost threefold increase in breast cancer risk for heterozygous female carriers in Central and Eastern Europe. ${ }^{18}$

Finally, some studies reported an elevated breast cancer risk in hereditary non-polyposis colorectal cancer (HNPCC/ Lynch syndrome, MIM no. 120435) caused by heterozygous mutations in DNA mismatch repair genes, mainly MLH1, MSH2, MSH6 and PMS2, ${ }^{27,28}$ whereas other investigations showed no or only a slightly increased breast cancer risk. ${ }^{29,30}$ At present, no special breast cancer surveillance is recommended for women with HNPCC, ${ }^{30-32}$ but this is mainly based on the investigation of heterozygous MLH1 and MSH2 mutation carriers, and there are indications that cancer risk associated with heterozygous MSH6 and PMS2 mutations may differ. ${ }^{30}$

\section{Rare intermediate-penetrance breast cancer susceptibility genes}

As BRCA1 and BRCA2 are involved in DNA repair, and heterozygous mutations in DNA repair genes such as ATM and TP53 have been discussed to be associated with an increased breast cancer risk, candidate gene approaches to identify further breast cancer susceptibility genes in highrisk families concentrated on genes involved in DNA repair such as CHEK2, RAD50, BRIP1 and PALB2. The link between DNA repair and breast cancer susceptibility became even more intriguing after homozygous mutations in BRCA2 were found to be responsible for Fanconi anaemia, and $B R C A 2$ was shown to be identical with FANCD1. ${ }^{33,34}$ Notably, mutations in several genes associated with an increased breast cancer risk in monoallelic mutation carriers cause rare subgroups of Fanconi anaemia or other rare autosomal recessive diseases, if both alleles are affected. For example, BRIP1 and PALB2, both associated with a moderately increased risk in heterozygous mutation carriers, turned out to be FANCJ and FANCN, respectively (Figure 1). It is beyond the scope of this review to discuss DNA repair and Fanconi anaemia in detail. Interested readers are referred to the excellent reviews by Wang, ${ }^{34}$ Hakem, ${ }^{35}$ and D'Andrea and Grompe. ${ }^{36}$ Odds ratios for heterozygous mutations in DNA repair genes such as ATM, CHEK2, BRIP1, PALB2 and RAD50 lie between 2.0 and 4.3 and are thus associated with a moderately increased breast cancer risk (Table 2$).^{26}$

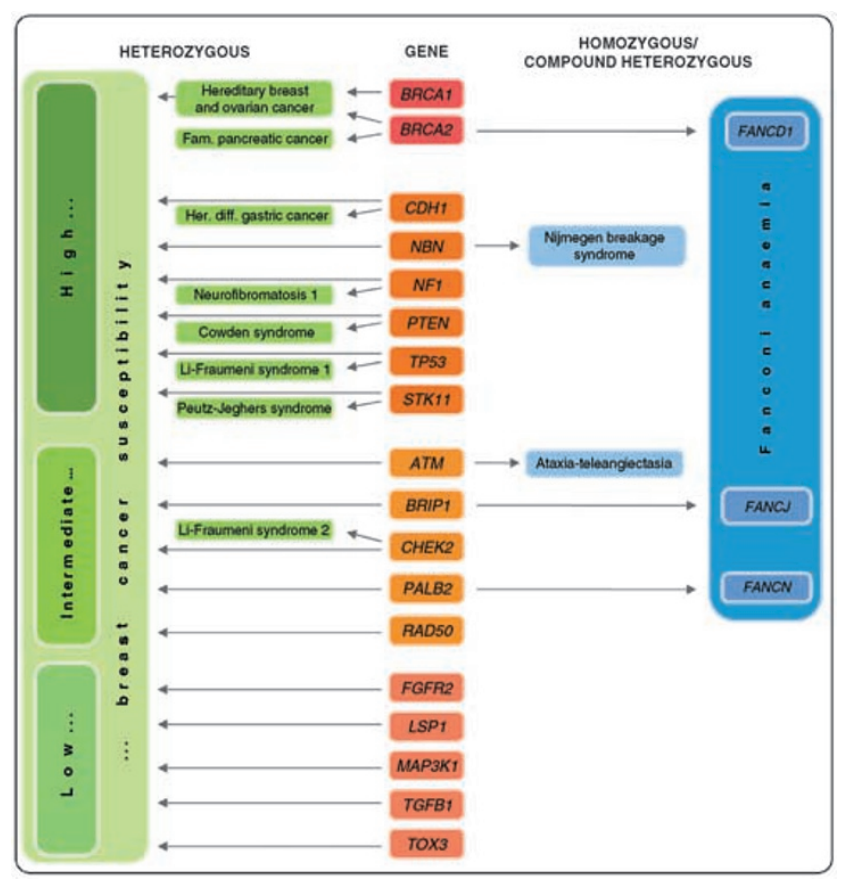

Figure 1 Genotype-phenotype correlation of heterozygous and homozygous/compound heterozygous mutation carriers for breast cancer predisposition genes and low-penetrance breast cancer susceptibility SNPs. Besides BRCA1 and BRCA2, genes are grouped by association with cancer predisposition syndromes (Table 1 ), rare intermediate penetrance breast cancer susceptibility genes (Tables 2 and 3), and common low-penetrance breast cancer susceptibility single nucleotide polymorphisms (Tables 2 and 3). Genes are listed in alphabetical order in each group. 
Table 2 Breast cancer susceptibility genes and single nucleotide polymorphisms

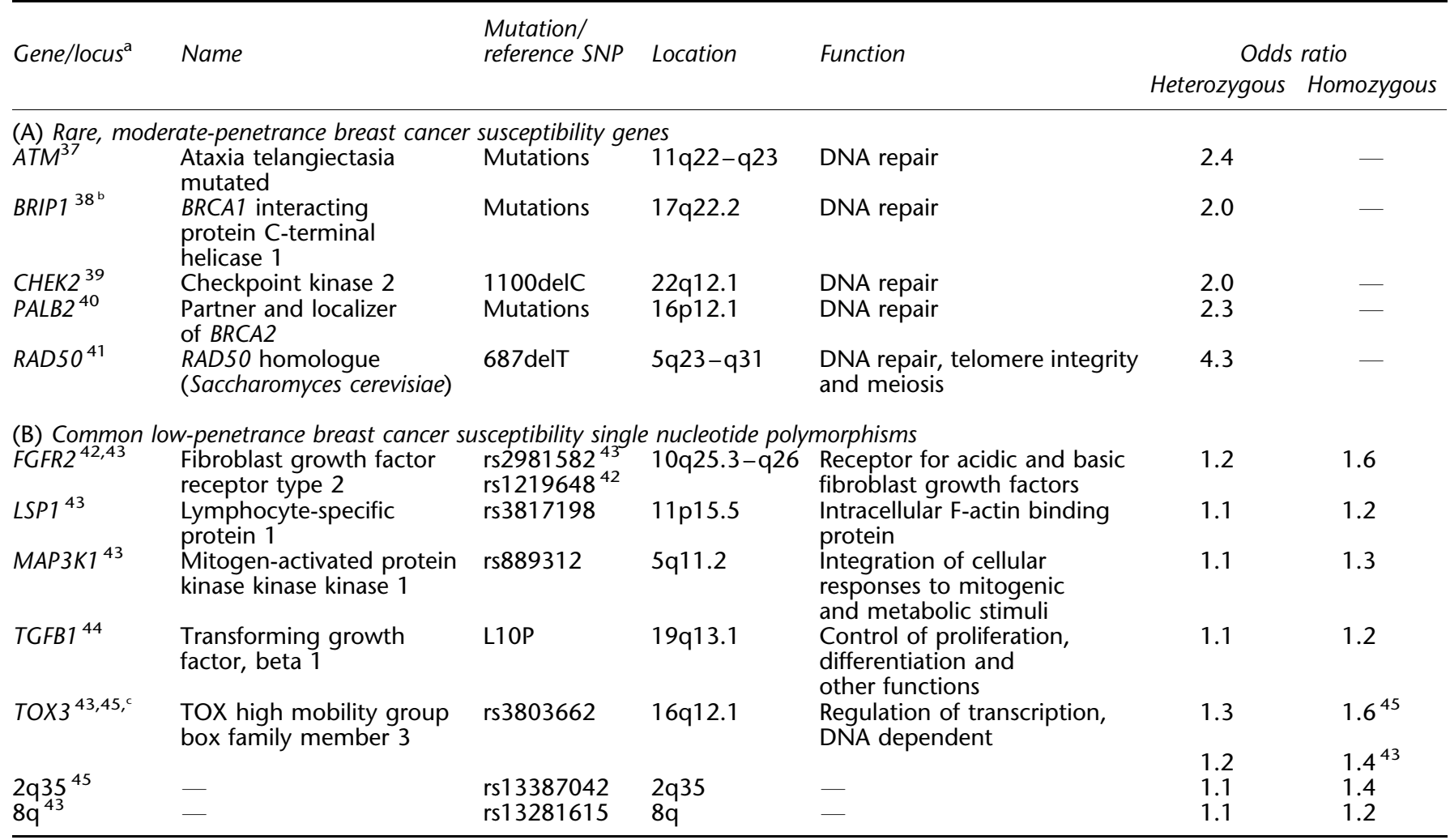

${ }^{\mathrm{a}}$ Alphabetical order.

${ }^{\mathrm{b}}$ Formerly known as $\mathrm{BACH} 1$.

'Formerly known as TNRC9.

ATM mutations are known to cause ataxia teleangiectasia (Louis-Bar syndrome), an autosomal recessive disorder characterized by cerebellar ataxia, telangiectases, immune defects and a predisposition to malignancy (MIM no. 208900). Increased breast cancer risk in heterozygous mutation carrier females has been controversial for nearly 20 years. ${ }^{37,46}$ Estimated relative risk varied from 1.3 to 12.7 in different studies. ${ }^{4}$ Most recently, screening of 441 BRCA1/BRCA2-negative breast cancer cases from 440 families and 521 controls for ATM sequence variants identified 12 mutations in affected individuals and 2 in controls. By segregation analysis incorporating information from the controls and the full pedigrees of the cases, Renwick et $a l^{37}$ estimated a relative breast cancer risk of 2.37 in heterozygous mutation carriers. Therefore, ATM can currently be classified as a breast cancer susceptibility gene with intermediate penetrance.

Cell cycle checkpoint kinase 2 (CHEK2), a conserved signalling component in DNA repair, is activated by ATM in response to DNA double-strand breaks and subsequently phosphorylates BRCA1. Mutations in CHEK2 rarely cause LFS2 (MIM no. 609265). No clear relationship with breast cancer risk was found for several sequence alterations of CHEK2. ${ }^{48}$ In contrast, CHEK2 1100 delC in exon 10, leading to an abolished kinase function, displayed a twofold increased breast cancer risk in female heterozygous mutation carriers. ${ }^{39}$ Most recently, the results of a meta-analysis for the assessment of breast cancer risk in CHEK2 1100delC carriers of more than 50000 cases and controls reported on a 4.8 relative risk of developing breast cancer for heterozygous CHEK2 1100delC mutation carriers with a family history of breast cancer. This leads to an estimated cumulative breast cancer risk of $37 \%$ by the age of 70 years. ${ }^{49}$ Carrier frequency in the Netherlands reaches up to $0.8 \%$ and in Finland and Sweden up to 0.7 and $0.5 \%$, respectively. Allele frequencies in other European countries, North America and Australia rarely exceed 0.1 or $0.2 \%$, meaning 1 or 2 in 1000 alleles (Table 3). ${ }^{39,50}$ In addition, screening of all 14 coding exons in 516 BRCA1/ $B R C A 2$ mutation-negative hereditary breast cancer families displayed independent segregation of CHEK2 1100delC with breast cancer in two of four families analysed, ${ }^{51}$ and the initially reported high risk for male breast cancer has not been confirmed. ${ }^{39}$ However, CHEK2 1100delC carriers 
Table 3 Frequency of mutations in breast cancer susceptibility genes and common single nucleotide polymorphisms

\begin{tabular}{|c|c|c|c|}
\hline Gene/locus ${ }^{\mathrm{a}}$ & Mutation/reference SNP & Allele frequency & $\%$ \\
\hline \multicolumn{4}{|c|}{ (A) Rare, moderate-penetrance breast cancer susceptibility genes } \\
\hline ATM & Mutations & Western population & $0.25-0.5^{46}$ \\
\hline$B R I P 1^{\mathrm{b}}$ & Mutations & UK & $0.15^{38}$ \\
\hline \multirow[t]{12}{*}{ CHEK2 } & 1100delC & The Netherlands & $0.65-0.8^{39}$ \\
\hline & & Finland & $0.55-0.7^{39}$ \\
\hline & & UK & $0.18-0.25^{39}$ \\
\hline & & Germany & $0.075-0.125^{39}$ \\
\hline & & Australia & $0.07^{39}$ \\
\hline & & Sweden & $0.3-0.5^{39}$ \\
\hline & & Poland & $0.1-0.125^{39}$ \\
\hline & & Czech Republic & $0.15^{39}$ \\
\hline & & Italy & $0.055^{39}$ \\
\hline & & USA & $0.15-0.2^{39}$ \\
\hline & & Canada & $0.1^{39}$ \\
\hline & & Spain & No detection ${ }^{39,50}$ \\
\hline PALB2 & Mutations & ÚK & $0.25^{40}$ \\
\hline RAD50 & 687 delT & Finland & $0.5^{41}$ \\
\hline \multicolumn{4}{|c|}{ (B) Common low-penetrance breast cancer susceptibility single nucleotide polymorphisms } \\
\hline \multirow[t]{3}{*}{ FGFR2 } & rs1219648 & USA/European ancestry & $39^{42}$ \\
\hline & rs2981582 & UK & $38^{43}$ \\
\hline & & Asia & $30^{43}$ \\
\hline \multirow{2}{*}{ LSP1 } & rs3817198 & UK & $30^{43}$ \\
\hline & & Asia & $14^{43}$ \\
\hline \multirow[t]{2}{*}{ MAP3К1 } & rs889312 & UK & $28^{43}$ \\
\hline & & Asia & $54^{43}$ \\
\hline & L10P & BCAC & $38^{44}$ \\
\hline \multirow[t]{3}{*}{$T O X 3^{\mathrm{C}}$} & rs3803662 & Western population & $14^{45}$ \\
\hline & & UK & $25^{43}$ \\
\hline & & Asia & $60^{43}$ \\
\hline $2 q 35$ & rs13387042 & Western population & $25^{45}$ \\
\hline \multirow[t]{2}{*}{$8 q$} & rs13281615 & UK & $40^{43}$ \\
\hline & & Asia & $56^{43}$ \\
\hline
\end{tabular}

BCAC, Breast Cancer Association Consortium, international collaboration group.

${ }^{a}$ Alphabetical order.

${ }^{\mathrm{b}}$ Formerly known as $\mathrm{BACH} 1$.

'Formerly known as TNRC9.

seem to have both poorer disease-free and overall survival than non-carriers, and an increased risk of developing a second, mostly contralateral breast cancer has been observed in CHEK2 1100delC mutation carriers having received initial radiotherapy. ${ }^{52}$ Weischer et al ${ }^{49}$ proposed CHEK2 1100delC genotyping of women counsellees of Northern or Eastern European descent with a family history of breast cancer. In contrast, Offit and Garber, ${ }^{53}$ taking into account the very low frequency of CHEK2 1100delC mutations in most Western populations, felt it currently does not seem to be justified to routinely test for CHEK2 110delC to guide the clinical management.

Mutations in BRIP1, previously known as BACH1, were demonstrated to be associated with an increased breast cancer risk. Screening for constitutional BRIP1 mutations in 1212 individuals with breast cancer from $B R C A 1 / B R C A 2$ mutation-negative families and 2081 controls identified nine and two truncating mutations in individuals with breast cancer and controls, respectively. This leads to an estimated relative risk of breast cancer of 2.0 in hetero- zygous mutation carriers, whereas biallelic mutations cause Fanconi anaemia, complementation group J (MIM no. 609054). ${ }^{38}$

Investigations of PALB2, known to cause Fanconi anaemia, complementation group N (MIM no. 610832), in 923 individuals from different families with hereditary breast cancer and 1084 healthy control individuals led to the identification of 10 truncating PALB2 mutations in individuals with familial breast cancer, whereas there were no truncating mutations in controls. ${ }^{40}$ Similar to former reports on breast cancer families carrying mutations in ATM, CHEK2 or BRIP1, ${ }^{37,38,51,54}$ Rahman et al ${ }^{40}$ reported that only two of four first-degree breast cancer-affected relatives of breast cancer probands with PALB2 mutations also carried the PALB2 mutations, indicating an incomplete segregation of $P A L B 2$ mutations with breast cancer and thereby mirroring the difficulties of screening these genes in breast cancer families when unaffected women ask for predictive molecular testing to specify their individual breast cancer risk. In addition, ATM, BRIP1, CHEK2 and 
PALB2 mutations, classified as rare breast cancer susceptibility mutations with intermediate penetrance, collectively account for only approximately $2.3 \%$ of the overall familial risk. ${ }^{40}$

$R A D 50$ encodes a protein essential for double-stranded DNA break repair interacting with BRCA1 and NBN. In this gene, Heikkinen et $a l^{41}$ identified the Finnish founder mutation 687delT, which is associated with an increased breast cancer risk (odds ratio 4.3) in the Finnish cohort $(n=317)$. But, subsequent analyses in additional cohorts from Sweden, Norway and Iceland $(n=512)$ failed to identify the mutation, thus again indicating the high frequency of certain mutations in distinct populations that has to be considered if molecular screening is discussed.

\section{Common low-penetrance breast cancer susceptibility SNPs}

New tools such as high-density SNP arrays are now available for genome-wide association studies to decipher genetic variants associated with an increased breast cancer risk in large groups containing hundreds and thousands of patients and controls. The aim of these studies is to identify a number of polymorphisms, each expected to impact only to a minor extent on the individual risk. Nevertheless, as most of these variants occur with high frequency in the investigated populations (Table 3), they have a significant impact on the breast cancer risk but can also frequently be found in control cohorts. ${ }^{8}$ To understand how these genetic variants function and interact, and whether and how they modify environmental risk factors, it will be necessary to characterize their role in tumorigenesis. Currently, there is a growing list of reports on common SNPs in genes or chromosomal loci that have been identified in genome-wide association studies: FGFR2, ${ }^{42,43}$ LSP1, ${ }^{43}$ MAP3K1, ${ }^{43}$ TGFB1, ${ }^{44}$ TOX $3,{ }^{43,45}$ as well as a locus on $2 \mathrm{q}^{3} 5^{45}$ and $8 \mathrm{q} .{ }^{43}$ The odds ratios for heterozygous and homozygous carriers range between 1.1 and 1.3 , and 1.2 and 1.6, respectively (Table 2). Notably, although rare mutations in ATM, BRCA1, BRCA2, CHEK2 and TP53 are known to be associated with increased breast cancer risk, Baynes et $a l^{55}$ recently reported that no significant breast cancer association of a common SNP or a certain combination of SNPs could be identified in any of these genes in 4474 investigated breast cancer cases from the British, East Anglian SEARCH study. In addition, Cox et $a l,{ }^{44}$ screening nine SNPs for which there was some prior evidence of breast cancer association, reported on a common SNP in CASP8 (rs1045485) that reduces breast cancer risk. For a critical discussion of the epidemiological credibility of these studies that depends on the number of investigations and patients included, replication and protection from bias, and regarding different genome-wide approaches for the identification of susceptibility genes, please refer to the review by $\operatorname{Risch}^{56}$ as well as the most recently published review by Seng and Seng. ${ }^{57}$

For example, two SNPs in intron 2 of FGFR2 (rs2981582 and rs1219648), a gene which is known to be amplified and overexpressed in sporadic breast cancer cases, ${ }^{58}$ has been observed in two independent multicentre genome-wide association studies of SNPs, leading to an increased breast cancer risk with an odds ratio in a heterozygous situation of $1.23-1.24 .^{42,43}$ However, $47-48 \%$ of the healthy control cohorts also carry these SNPs, ${ }^{8}$ mirroring the difficulties to use them in predictive testing in breast cancer families as well as in women without a family history of breast cancer.

Interestingly, a recent report of a three-phase genomewide association study in Ashkenazi Jews ${ }^{59}$ confirmed the formerly reported ${ }^{42,43}$ association of breast cancer risk with the chromosomal region of FGFR2 on 10q and observed a new breast cancer risk locus in 6q22.33 (odds ratio 1.41) comparing BRCA1/BRCA2-negative high-risk breast cancer cases with unaffected controls. Although functional or biological consequences of most SNPs are as yet unknown, ${ }^{7}$ Meyer et $a l^{60}$ recently reported on an altered binding affinity for transcription factors OCT1, RUNX2 and C/EBP $\beta$ as a result of identified breast cancer susceptibility SNPs in intron 2 of FGFR2 that lead to an increased FGFR2 expression.

Currently, further genome-wide association studies are underway comparing $B R C A 1 / B R C A 2$-negative high-risk breast cancer and sporadic breast cancer cases with control cohorts. They will certainly identify new susceptibility polymorphisms and will possibly be able to investigate additional or synergistic effects of defined susceptibility polymorphisms. ${ }^{6}$

\section{Modifiers in BRCA1 and BRCA2 mutation carriers}

There have been several observations supporting the hypothesis that breast cancer risk in BRCA1 and BRCA2 mutation carriers is modified by genetic factors. ${ }^{61}$ Taking into account that women tested negative for their familial BRCA1/BRCA2 mutations still face an increased breast cancer risk, $^{62}$ one can speculate that this increased risk might be due to inherited genetic variants that act as modifier genes in $B R C A 1 / B R C A 2$ mutation carriers, and also as low penetrance susceptibility polymorphisms in $B R C A 1 / B R C A 2$ mutation non-carriers. Currently, vast efforts are being made to identify modifier genes in $B R C A 1$ or BRCA2 mutation carriers (see eg, the Consortium of Investigators of Modifiers of BRCA1 and BRCA2 $(\mathrm{CIMBA}) .^{63}$ An SNP $135 \mathrm{G}>\mathrm{C}($ RAD51: c. $-98 \mathrm{G}>\mathrm{C})$ in $R A D 51$ has recently been identified as first modifier in BRCA2 mutation carriers, whereas no effect of this SNP was found in BRCA1 mutation carriers and BRCA1/BRCA2 mutation non-carriers. ${ }^{64,65} \mathrm{~A}$ multicentre study, investigating 10358 mutation carriers, described modifier roles for SNPs in FGFR2, MAP3K1 and TOX3 that were initially identified as low-penetrance breast cancer susceptibility 
SNPs. ${ }^{43}$ Importantly, the SNPs rs2981582 and rs889312 in FGFR2 and MAP3K1, respectively, increase the breast cancer risk in BRCA2 mutation carriers but not in BRCA1 mutation carriers, whereas rs3803662, an SNP in TOX3, is associated with an increased breast cancer risk in both BRCA1 and BRCA2 mutation carriers. ${ }^{66}$

\section{Discussion}

After the major breast cancer susceptibility genes BRCA1 and BRCA2 were cloned in 1994 and 1995, respectively, ${ }^{67}$ considerable efforts have been made to identify another susceptibility gene in high-risk families, ${ }^{26}$ but the predicted BRCA3 could not be found. ${ }^{4,67}$ At present, it seems to be widely accepted that no further high-penetrance genes accounting for a relevant number of familial cases exist. Instead, breast cancer is considered a complex disease determined by the combined effect of several or even many genetic variants. ${ }^{43}$ Generally, two groups of susceptibility factors can be clearly distinguished comparing mean allele frequencies and mean associated risks: rare mutations in genes involved in DNA repair with intermediate penetrance on the one side and low penetrance SNPs on the other (Figure 2).

At present, a vast amount of new data is generated by candidate gene approaches and genome-wide association studies. Although criteria for genetic testing of BRCA1 and BRCA2 have been defined, ${ }^{9-14}$ and several models for determining carrier probabilities and cancer risks of individuals with a family history of breast cancer are publicly available, ${ }^{68-70}$ it is still a matter of debate whether, when and how the increasing list of genetic susceptibility factors can be integrated into routine clinical care. So far, no clinical decisions can be based on their presence or absence, and genetic testing may currently only provoke great insecurity, ${ }^{8}$ both for counsellees and medical doctors. As discussed by Offit and Garber, ${ }^{53}$ routine investigation may actually lead to unnecessary interventions in carriers of susceptibility mutations and

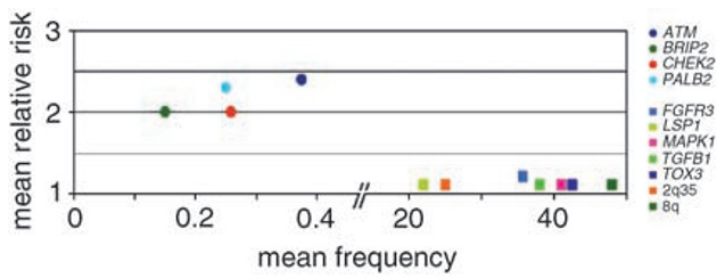

Figure 2 Association of mean frequency and relative risk of breast cancer susceptibility genes and loci. On the basis of the information in Tables 2 and 3, the association of mean frequency and mean breast cancer-associated relative risk is displayed illustrating the clear differences between rare mutations in genes involved in DNA repair with intermediate penetrance on the one side and common low penetrance single nucleotide polymorphisms on the other. non-carriers may feel a false sense of security. Genetic counselling of $B R C A 1 / B R C A 2$ mutation carriers regarding modifier polymorphisms such as FGFR2, TOX3, MAP3K1 and $R A D 51$, may be the easiest task because (i) the additional analysis of certain polymorphisms may specify the breast cancer risk and allow further individualization of the clinical management regarding the surveillance programme, decision-making concerning risk-reducing surgery and therapy, (ii) this is relevant for a small group of about $3 \%$ of all breast cancer patients, and most importantly, (iii) clinical programmes to meet this high risk have been set up in most countries. ${ }^{14,71}$ At present, complete sequencing of intermediate penetrance genes such as ATM, BRIP1, CHEK2, PALB2 or RAD50 in BRCA1/ $B R C A 2$-negative high-risk breast cancer families does not appear to be justified. Mutations in these genes are extremely rare in most populations and, even more importantly, the clinical consequences are not yet clear, especially regarding the incomplete segregation of the known mutation with breast cancer in affected families. ${ }^{37,38,40,51,72}$ It has to be considered that mutations, at least in some of these genes, are not specific for BRCA1/ $B R C A 2$ mutation-negative familial cases, but can also occur in sporadic breast cancer cases (Bogdanova et al, ${ }^{73}$ Erkko et $a l^{74}$ and A Meindl, unpublished data). Therefore, it is likely that predisposing mutations with moderate penetrance in other genes will be identified in families with multiple cases. Subsequently, this knowledge as well as the potential risk-modifying interaction of these mutations with predisposing polymorphisms may be an attractive tool for risk prediction.

Nevertheless, in the near future, as soon as costs and time of sequencing are reduced to a more reasonable level, it may become cost-effective to screen all genes involved in DNA repair or other breast cancer-associated pathways in high-risk families. Because of the known differences in allele frequency, for example, the rather high frequency of CHEK2 1100delC in the Netherlands or Finland, genetic testing of certain mutations and/or polymorphisms associated with a significantly increased breast cancer risk may only be indicated in populations with relatively high allele frequencies, because significant reduction of disease burden can only be achieved in a certain population if an effective preventive management is available, and the polymorphism or mutation is sufficiently frequent.

In addition to the identification of new polymorphisms and the validation of their relative risk in different large cohorts, it will be essential to understand the combined effect of different polymorphisms, and to establish reliable risk prediction models before stepping forward to routine investigations. Given seven established common breast cancer susceptibility SNPs, there are 2187 possible combinations of genotypes. ${ }^{75}$ Although risks conferred by individual loci are rather small, some risk alleles seem to act multiplicatively. Thus, the breast cancer risk among 
women carrying 14 risk alleles is estimated to be six times as high as among women carrying none of these risk alleles. $^{75}$ In the future, screening programmes may be adapted to the individual genetic risk, for example, modifying age of initiation and investigation intervals of mammography, integration of magnetic resonance imaging and/or risk-reducing surgery. It is to be hoped that this will lead to an intensified screening in high-risk individuals, but spare unnecessary and even potentially harmful screening in women with very low-risk profiles. However, the clinical utility of such an individualized genome-based approach has to be validated, and principles for the implementation of genetic testing of new susceptibility mutations and/or polymorphisms have to be established from an individual as well as from a population and health-care system point of view. ${ }^{76-78}$ Further studies will probably identify polymorphisms associated with different response rates to certain therapies or histological subtypes and particular SNPs may even serve as therapeutic targets. ${ }^{45,79,80}$ Taking full advantage of these polymorphisms will require functional characterization of the polymorphisms, as for instance for an SNP in intron 2 of FGFR2 leading to an altered binding affinity for transcriptional factors and thereby, to an increased FGFR2 expression. ${ }^{60}$

In summary, based on the current knowledge, there is no evidence that justifies screening of common low penetrance genes and loci to specify the individual breast cancer risk. In the near future, with the new generation of low-cost high-throughput sequencing technologies and powerful risk prediction models integrating family history, lifestyle factors and available genetic information, individual risk classification may allow adequate preventive management, intensified in those with higher risks but reduced in those with lower risk levels. With these powerful, validated risk estimation tools in hand, we will hopefully reach a point where statistical significance meets clinical relevance, and screening programmes based on genetic information will lead to reduced breast cancerassociated mortality.

\section{Acknowledgements}

We thank Doris Steinemann for her critical review of the paper and Gillian Teicke for her assistance in editing the paper.

\section{References}

1 Robson M, Offit K: Clinical practice. Management of an inherited predisposition to breast cancer. N Engl J Med 2007; 357: 154-162.

2 Bradbury AR, Olopade OI: Genetic susceptibility to breast cancer. Rev Endocr Metab Disord 2007; 8: 255-267.

3 Wooster R, Weber BL: Breast and ovarian cancer. $N$ Engl J Med 2003; 348: 2339-2347.

4 Nathanson KL, Wooster R, Weber BL: Breast cancer genetics: what we know and what we need. Nat Med 2001; 7: 552-556.

5 Meindl A: Comprehensive analysis of 989 patients with breast or ovarian cancer provides BRCA1 and BRCA2 mutation profiles and frequencies for the German population. Int J Cancer 2002; 97: $472-480$.

6 Turnbull C, Rahman N: Genetic predisposition to breast cancer: past, present, and future. Annu Rev Genomics Hum Genet 2008; 9: $321-345$.

7 Stratton MR, Rahman N: The emerging landscape of breast cancer susceptibility. Nat Genet 2008; 40: 17-22.

8 Willems PJ: Susceptibility genes in breast cancer: more is less? Clin Genet 2007; 72: 493-496.

9 American Society of Clinical Oncology: American Society of Clinical Oncology policy statement update: genetic testing for cancer susceptibility. J Clin Oncol 2003; 21: 2397-2406.

10 Bachmann K, Bartram CR, Chang-Claude J, Fonatsch C, Propping P: Richtlinien zur Diagnostik der genetischen Disposition für Krebserkrankungen. Deutsches Ärzteblatt 1998; 95: A1396-A1403.

11 Dietel M, Harms E, Honnefelder L et al: Bekanntmachungen: Richtlinien zur prädiktiven genetischen Diagnostik. Deutsches Ärzteblatt 2003; 100: A1297-A1305.

12 Schmutzler R, Schlegelberger B, Meindl A, Gerber WD, Kiechle M: [Counselling, genetic testing and prevention in women with hereditary breast- and ovarian cancer. Interdisciplinary recommendations of the consortium 'Hereditary Breast- and Ovarian Cancer' of the German Cancer AiD]. Zentralbl Gynakol 2003; 125: 494-506.

13 Eisinger F, Alby N, Bremond A et al: Recommendations for medical management of hereditary breast and ovarian cancer: the French National ad hoc Committee. Ann Oncol 1998; 9: 939-950.

14 McIntosh A, Shaw C, Evans G et al: Clinical Guidelines and Evidence Review for the Classification and Care of Women at Risk of Familial Breast Cancer (NICE Guidelines CG014). London: National Collaborating Centre for Primary Care, University of Sheffield, 2004.

15 Guenard F, Labrie Y, Ouellette G et al: Germline mutations in the breast cancer susceptibility gene PTEN are rare in high-risk nonBRCA1/2 French Canadian breast cancer families. Fam Cancer 2007; 6: 483-490.

16 Kaurah P, MacMillan A, Boyd N et al: Founder and recurrent CDH1 mutations in families with hereditary diffuse gastric cancer. JAMA 2007; 297: 2360-2372.

17 Sharif S, Moran A, Huson SM et al: Women with neurofibromatosis 1 are at a moderately increased risk of developing breast cancer and should be considered for early screening. J Med Genet 2007; 44: 481-484.

18 Bogdanova N, Feshchenko S, Schurmann P et al: Nijmegen breakage syndrome mutations and risk of breast cancer. Int $J$ Cancer 2007; 122: 802-806.

19 Hearle N, Schumacher V, Menko FH et al: Frequency and spectrum of cancers in the Peutz-Jeghers syndrome. Clin Cancer Res 2006; 12: 3209-3215.

20 Garber JE, Goldstein AM, Kantor AF, Dreyfus MG, Fraumeni Jr JF, Li FP: Follow-up study of twenty-four families with Li-Fraumeni syndrome. Cancer Res 1991; 51: 6094-6097.

21 NCCN Clinical Practice Guidelines in Oncology: Genetic/familial high risk assessment: breast and ovarian. Version I. 2008, www.nccn. org/professionals/physician_gls/PDF/genetics_screening.pdf.

22 Lynch HT, Lynch JF, Lynch PM, Attard T: Hereditary colorectal cancer syndromes: molecular genetics, genetic counseling, diagnosis and management. Fam Cancer 2008; 7: 27-39.

23 Saal LH, Gruvberger-Saal SK, Persson C et al: Recurrent gross mutations of the PTEN tumor suppressor gene in breast cancers with deficient DSB repair. Nat Genet 2008; 40: 102-107.

24 Masciari S, Larsson N, Senz J et al: Germline E-cadherin mutations in familial lobular breast cancer. J Med Genet 2007; 44: 726-731.

25 Schrader KA, Masciari S, Boyd N et al: Hereditary diffuse gastric cancer: association with lobular breast cancer. Fam Cancer 2008; 7: $73-82$.

26 Walsh T, King MC: Ten genes for inherited breast cancer. Cancer Cell 2007; 11: 103-105.

27 Vasen HF, Morreau H, Nortier JW: Is breast cancer part of the tumor spectrum of hereditary nonpolyposis colorectal cancer? Am J Hum Genet 2001; 68: 1533-1535. 
28 Risinger JI, Barrett JC, Watson P, Lynch HT, Boyd J: Molecular genetic evidence of the occurrence of breast cancer as an integral tumor in patients with the hereditary nonpolyposis colorectal carcinoma syndrome. Cancer 1996; 77: 1836-1843.

29 Geary J, Sasieni P, Houlston R et al: Gene-related cancer spectrum in families with hereditary non-polyposis colorectal cancer (HNPCC). Fam Cancer 2008; 7: 163-172.

30 Watson P, Vasen HF, Mecklin JP et al: The risk of extra-colonic, extra-endometrial cancer in the Lynch syndrome. Int $J$ Cancer 2008; 123: 444-449.

31 Lindor NM, Petersen GM, Hadley DW et al: Recommendations for the care of individuals with an inherited predisposition to Lynch syndrome: a systematic review. JAMA 2006; 296: 1507-1517.

32 Vasen HF, Moslein G, Alonso A et al: Guidelines for the clinical management of Lynch syndrome (hereditary non-polyposis cancer). J Med Genet 2007; 44: 353-362.

33 Howlett NG: Fanconi anemia: Fanconi anemia, breast and embryonal cancer risk revisited. Eur J Hum Genet 2007; 15: 715-717.

34 Wang W: Emergence of a DNA-damage response network consisting of Fanconi anaemia and BRCA proteins. Nat Rev Genet 2007; 8: 735-748.

35 Hakem R: DNA-damage repair; the good, the bad, and the ugly. EMBO J 2008; 27: 589-605.

36 D'Andrea AD, Grompe M: The Fanconi anaemia/BRCA pathway. Nat Rev Cancer 2003; 3: 23-34.

37 Renwick A, Thompson D, Seal S et al: ATM mutations that cause ataxia-telangiectasia are breast cancer susceptibility alleles. Nat Genet 2006; 38: 873-875.

38 Seal S, Thompson D, Renwick A et al: Truncating mutations in the Fanconi anemia J gene BRIP1 are low-penetrance breast cancer susceptibility alleles. Nat Genet 2006; 38: 1239-1241.

39 Nevanlinna H, Bartek J: The CHEK2 gene and inherited breast cancer susceptibility. Oncogene 2006; 25: 5912-5919.

40 Rahman N, Seal S, Thompson D et al: PALB2, which encodes a BRCA2-interacting protein, is a breast cancer susceptibility gene. Nat Genet 2007; 39: 165-167.

41 Heikkinen K, Rapakko K, Karppinen SM et al: RAD50 and NBS1 are breast cancer susceptibility genes associated with genomic instability. Carcinogenesis 2006; 27: 1593-1599.

42 Hunter DJ, Kraft P, Jacobs KB et al: A genome-wide association study identifies alleles in FGFR2 associated with risk of sporadic postmenopausal breast cancer. Nat Genet 2007; 39: 870-874.

43 Easton DF, Pooley KA, Dunning AM et al: Genome-wide association study identifies novel breast cancer susceptibility loci. Nature 2007; 447: 1087-1093.

44 Cox A, Dunning AM, Garcia-Closas $M$ et al: A common coding variant in CASP8 is associated with breast cancer risk. Nat Genet 2007; 39: 352-358.

45 Stacey SN, Manolescu A, Sulem P et al: Common variants on chromosomes $2 \mathrm{q} 35$ and $16 \mathrm{q} 12$ confer susceptibility to estrogen receptor-positive breast cancer. Nat Genet 2007; 39: 865-869.

46 Ahmed M, Rahman N: ATM and breast cancer susceptibility. Oncogene 2006; 25: 5906-5911.

47 Angele S, Hall J: The ATM gene and breast cancer: is it really a risk factor? Mutat Res 2000; 462: 167-178.

48 Bell DW, Kim SH, Godwin AK et al: Genetic and functional analysis of CHEK2 (CHK2) variants in multiethnic cohorts. Int J Cancer 2007; 121: 2661-2667.

49 Weischer M, Bojesen SE, Ellervik C, Tybjaerg-Hansen A, Nordestgaard BG: CHEK2*1100delC genotyping for clinical assessment of breast cancer risk: meta-analyses of 26000 patient cases and 27000 controls. J Clin Oncol 2008; 26: 542-548.

50 Osorio A, Rodriguez-Lopez R, Diez $\mathrm{O}$ et al: The breast cancer low-penetrance allele 1100delC in the CHEK2 gene is not present in Spanish familial breast cancer population. Int J Cancer 2004; 108: $54-56$.

51 Dufault MR, Betz B, Wappenschmidt B et al: Limited relevance of the CHEK2 gene in hereditary breast cancer. Int J Cancer 2004; 110: $320-325$.
52 Schmidt MK, Tollenaar RA, de Kemp SR et al: Breast cancer survival and tumor characteristics in premenopausal women carrying the CHEK2*1100delC germline mutation. J Clin Oncol 2007; 25: 64-69.

53 Offit K, Garber JE: Time to check CHEK2 in families with breast cancer? J Clin Oncol 2008; 26: 519-520.

54 Meijers-Heijboer $\mathrm{H}$, van den $\mathrm{OA}$, Klijn $\mathrm{J}$ et al: Low-penetrance susceptibility to breast cancer due to $\mathrm{CHEK} 2\left(^{*}\right) 1100 \mathrm{delC}$ in noncarriers of BRCA1 or BRCA2 mutations. Nat Genet 2002; 31: 55-59.

55 Baynes C, Healey CS, Pooley KA et al: Common variants in the ATM BRCA1, BRCA2, CHEK2 and TP53 cancer susceptibility genes are unlikely to increase breast cancer risk. Breast Cancer Res 2007; 9: R27.

56 Risch NJ: Searching for genetic determinants in the new millennium. Nature 2000; 405: 847-856.

57 Seng KC, Seng CK: The success of the genome-wide association approach: a brief story of a long struggle. Eur J Hum Genet 2008; 16: $554-564$

58 Heiskanen M, Kononen J, Barlund $\mathrm{M}$ et al: CGH cDNA and tissue microarray analyses implicate FGFR2 amplification in a small subset of breast tumors. Anal Cell Pathol 2001; 22: 229-234.

59 Gold B, Kirchhoff T, Stefanov S et al: Genome-wide association study provides evidence for a breast cancer risk locus at $6 \mathrm{q} 22.33$. Proc Natl Acad Sci USA 2008; 105: 4340-4345.

60 Meyer KB, Maia AT, O’Reilly M et al: Allele-specific up-regulation of FGFR2 increases susceptibility to breast cancer. PLoS Biol 2008; 6: e108.

61 Antoniou AC, Easton DF: Models of genetic susceptibility to breast cancer. Oncogene 2006; 25: 5898-5905.

62 Smith A, Moran A, Boyd MC et al: Phenocopies in BRCA1 and BRCA2 families: evidence for modifier genes and implications for screening. J Med Genet 2007; 44: 10-15.

63 Chenevix-Trench G, Milne RL, Antoniou AC, Couch FJ, Easton DF, Goldgar DE: An international initiative to identify genetic modifiers of cancer risk in BRCA 1 and BRCA2 mutation carriers: the Consortium of Investigators of Modifiers of BRCA1 and BRCA2 (CIMBA). Breast Cancer Res 2007; 9: 104.

64 Kadouri L, Kote-Jarai Z, Hubert A et al: A single-nucleotide polymorphism in the RAD51 gene modifies breast cancer risk in BRCA2 carriers, but not in BRCA1 carriers or noncarriers. $\mathrm{Br} J$ Cancer 2004; 90: 2002-2005.

65 Antoniou AC, Sinilnikova OM, Simard J et al: RAD51 135G $\rightarrow$ C modifies breast cancer risk among BRCA2 mutation carriers: results from a combined analysis of 19 studies. Am J Hum Genet 2007; 81: 1186-1200.

66 Antoniou AC, Spurdle AB, Sinilnikova OM et al: Common breast cancer-predisposition alleles are associated with breast cancer risk in BRCA1 and BRCA2 mutation carriers. Am J Hum Genet 2008; 82: 937-948.

67 Narod SA, Foulkes WD: BRCA1 and BRCA2: 1994 and beyond. Nat Rev Cancer 2004; 4: 665-676.

68 Marroni F, Aretini P, D'Andrea E et al: Evaluation of widely used models for predicting BRCA1 and BRCA2 mutations. J Med Genet 2004; 41: 278-285.

69 Barcenas CH, Hosain GM, Arun B et al: Assessing BRCA carrier probabilities in extended families. J Clin Oncol 2006; 24: 354-360.

70 Antoniou AC, Cunningham AP, Peto J et al: The BOADICEA model of genetic susceptibility to breast and ovarian cancers: updates and extensions. Br J Cancer 2008; 98: 1457-1466.

71 Silva E, Gatalica Z, Snyder C, Vranic S, Lynch JF, Lynch HT: Hereditary breast cancer: part II. Management of hereditary breast cancer: implications of molecular genetics and pathology. Breast J 2008; 14: 14-24.

72 Meijers-Heijboer $\mathrm{H}$, van den OA, Klijn J et al: Low-penetrance susceptibility to breast cancer due to $\mathrm{CHEK} 2\left(^{*}\right) 1100 \mathrm{delC}$ in noncarriers of BRCA1 or BRCA2 mutations. Nat Genet 2002; 31: 55-59.

73 Bogdanova N, Feshchenko S, Cybulski C, Dork T: CHEK2 mutation and hereditary breast cancer. J Clin Oncol 2007; 25: e26.

74 Erkko H, Xia B, Nikkila J et al: A recurrent mutation in PALB2 in Finnish cancer families. Nature 2007; 446: 316-319. 
75 Pharoah PD, Antoniou AC, Easton DF, Ponder BA: Polygenes, risk prediction, and targeted prevention of breast cancer. N Engl J Med 2008; 358: 2796-2803.

76 Cassiman JJ: Research network: EuroGentest - a European Network of Excellence aimed at harmonizing genetic testing services. Eur J Hum Genet 2005; 13: 1103-1105.

77 Ginsburg GS: Genomic medicine: 'grand challenges' in the translation of genomics to human health. Eur J Hum Genet 2008; 16: 873-874.
78 Scheuner MT, Sieverding P, Shekelle PG: Delivery of genomic medicine for common chronic adult diseases: a systematic review. JAMA 2008; 299: 1320-1334.

79 Fagerholm R, Hofstetter B, Tommiska J et al: NAD(P)H:quinone oxidoreductase $1 \mathrm{NQO}{ }^{*} 2$ genotype (P187S) is a strong prognostic and predictive factor in breast cancer. Nat Genet 2008; 40: 844-853.

80 Garcia-Closas M, Hall P, Nevanlinna $\mathrm{H}$ et al: Heterogeneity of breast cancer associations with five susceptibility loci by clinical and pathological characteristics. PLoS Genet 2008; 4: e1000054. 